Alfonso Galindo y Enrique Ujaldón: La cultura política liberal. Pasado, presente y futuro. Madrid: Editorial Tecnos, 2014. 296 pp.

\title{
El liberal como héroe
}

\author{
Javier Adolfo Iglesias \\ Periodista y profesor de Filosofía
}

Llega este brillante ensayo editado por Tecnos para aportar una comprensión del liberalismo alejada de tópicos y trincheras, en una época en la que nuestra vida en común está llena de fórmulas, ideas fosilizadas y debates preconcebidos. El liberalismo que Alfonso Galindo y Enrique Ujaldón argumentan y exponen en 290 páginas huye de ellos y asume el conflicto, la paradoja y la inestabilidad que implica la permanente revisión de las creencias individuales y colectivas. Esta concepción y su práctica política asociada la definen como "el tercer liberalismo", pero no tanto como una síntesis de contrarios sino como tercer excluido de pares conceptuales asociados al liberalismo clásico y sus oponentes no menos clásicos, como son el totalitarismo o el republicanismo.

¿Cómo comprender que el defendido en este libro es un liberalismo sin dogmas por aquellos que hacen del estereotipo y el lugar común requisitos imprescindibles de cualquier debate y crítica en la era del espectáculo de la sociedad multipantalla? Ni siquiera el derecho a la propiedad, el mercado o el fundamento metafísico de la libertad son para los autores piedras inamovibles en el ámbito de la justificación. No hay dioses en este liberalismo, solo constataciones y revisiones de la realidad, la del individuo y la de los otros con un proyecto de vida en común, porque que la comunidad y la necesidad de la vida comunitaria sean necesarias no deja de sorprender a los liberales de cartilla que lean este ensayo.

Hasta que los autores perfilan su propuesta positiva en la segunda parte de esta obra, recorren conceptos, problemas y plasmaciones instrumentales concretas del llamado "liberalismo clásico". Hay tantos liberalismos como concreciones históricas y de ahí la elección del concepto "cultura liberal", que los engloba a todos y a los que une un "aire de familia" a modo wittgensteniano. Este recorrido histórico realizado en el capítulo I cumple la función más aproximada a lo que pueda ser un manual de ideas y de historia del liberalismo, un manual excelente para que los alumnos universitarios se introduzcan mediante la reflexión en autores como Locke, Adam Smith, Tocqueville o experiencias políticas tan dispares como la Revolución Francesa y la de los Estados Unidos de América. A ellas se aproximan desde su problematicidad. A modo de ejemplo sirve esta 
conclusión sobre John Stuart Mill: “Gran parte del liberalismo clásico evolucionó en la línea de Mill y se alió con la socialdemocracia en la defensa de lo que posteriormente se llamó el Estado del Bienestar. Pero parece difícil negar que en ese camino el liberalismo fue perdiendo paulatinamente su propia identidad hasta diluirse" (p. 60).

En la historia de las ideas es tristemente paradójico que teorías y doctrinas que son fórmulas, ideas cerradas o diseños disparatados aparezcan como grandes ideales y horizontes de la humanidad, y sin embargo el ideal del liberalismo se suele presentar con una fórmula deformada, bien como la del adorador del mercado, bien como el escondrijo del individualista egoísta. Ya en la introducción los autores definen lo que significan con "cultura política liberal", que trasciende una tradición de gobierno, una forma de Estado e incluso una doctrina económica, y sin embargo incluye a todas. La cultura política liberal no es "el liberalismo" al uso, ni se sitúa en un ring mediático de debate con "otras ideas", como el feminismo, el ecologismo o el nacionalismo. Afecta a los cimientos del ser humano y su ser social y, por ende, político.

Pese al amable aroma postmoderno que desprende La cultura política liberal, hay convicciones, principios y valores en sus páginas. El primero es el considerar metodológicamente al individuo como el sujeto político frente a otras supuestas entidades, como el pueblo o la nación. Un segundo es que la libertad del ser humano se da en comunidad, con y contra el Estado, que de forma neutral debería garantizar y promover la igualdad jurídica y política del individuo, nunca la económica. "Se precisa al Estado en orden a garantizar que los individuos puedan perseguir sus propios fines en el seno de la sociedad civil", afirman, al secundar la inevitabilidad de esta forma de organización espontánea y continua con las comunidades extensas.

Por ello es necesaria la distribución de poderes para evitar la coacción, a esquivar siempre, incluida la del mercado desregulado por unas empresas que en realidad buscan el monopolio. Finalmente, entre las creencias de estos liberales está la del diálogo permanente y la persuasión del mejor argumento como único criterio de organización colectiva a través de instituciones, normas y leyes.

Este libro no cita ni describe en detalle la actualidad, pero los autores no eluden problemas candentes como el de la justificación de la representación política en épocas de su desprestigio, la emigración, la mitificación nacionalista de la historia a través de la educación o el uso del deporte como adoctrinamiento. Hay referencias a la globalización y a la crisis financiera de 2009. Digamos que se puede leer los titulares diarios detrás de las reflexiones de estas páginas.

Aunque no tiene intención polemista, en el libro se deshacen tópicos y prejuicios sumergiendo al lector en la profundidad. "Porque todos somos liberales y no lo sabemos", podría haber sido un subtítulo alternativo. Particularmente en la España de hoy. Aparentemente no lo parece, pero la referencia en el subtítulo al presente nos indica que este es un libro necesario, casi urgente hoy día en España. Llega oportuno para alumbrar conceptualmente problemas que aparecen a diario 
en los informativos, en un momento en el que los conceptos son imágenes en los mal llamados "memes"; se confunden democracia y calle, internet y parlamento; en un momento en el que las palabras vuelan como trinos digitales sin apenas dejar otro rastro que la parodia, el cinismo y la ira. Podemos ser liberales en nuestras creencias políticas porque ya lo somos en nuestras vidas.

Pero este es un libro denso intelectualmente porque es filosófico; sus autores son catedráticos de Filosofía y brillantes pensadores activos del tiempo que les ha tocado vivir y en este sentido no es baladí señalar que de los muchos otros con los que dialogan, critican y apoyan pertenecen a las últimas décadas, entre ellos, Ackerman, Blumenberg, Rivera o José Luis Villacañas, profesor de los autores a quien está dedicada su obra, como señal, símbolo e indicio de su profundidad intelectual. ¿Qué añadir a tanto libro sobre liberalismo con vocación de recetario político y económico? Bases sólidas de pensamiento, epistemológicas y antropológicas por unos filósofos que rehúyen cualquier certeza metafísica del liberalismo clásico, el iusnaturalismo, por citar una. El tercer liberalismo es antidogmático, falibilista y pragmatista, pues se basa en una epistemología actual que arranca en Wittgenstein y Popper y que se prolonga hasta Quine, Davidson y Rorty.

El lector se convierte en pensador de la mano de Galindo y Ujaldón, e irá a lo largo de las páginas de este libro construyendo heurísticamente una frontera imaginaria liberal, siempre movible, en la que se puede confrontar y situar. A uno de los lados, y junto a los autores, están la igualdad jurídica y política de los individuos, las normas y procedimientos, la necesidad de la comunidad y la unidad política, la neutralidad del Estado y los límites a su poder coactivo, la mejora de la comunidad mediante la justicia redistributiva puntual, el mercado como instrumento más justo pero no exento de regularización, el debate y diálogo permanentes en la toma de decisiones a través de mecanismos como la representación política y la elaboración de normas revisables. Frente a ellos: la concepción de un ciudadano republicano virtuoso y participativo por obligación en la comunidad, la búsqueda de la felicidad colectiva y la determinación de bienes, valores y fines colectivos por un Estado expansivo y burocrático, la igualdad económica de todos y la consiguiente infeliz frustración, el apriorismo, el dogma, la verdad... Enemigos y adversarios del liberalismo que Ujaldón y Galindo abordan en el capítulo cuarto de La cultura política liberal. El dogmatismo y el cinismo son las únicas trincheras que se encuentran en este ensayo porque las amenazas del totalitarismo y la anarquía están siempre ahí, como enseña la ciceroniana historia.

"No pretendemos ser originales", afirman los autores. Y sin embargo lo son al llevar al lector a zonas de oscuridad y sombras donde el pensamiento se detiene fascinado y también todo lector que se deje llevar sin urgencias. Son momentos en los que late un cierto pesimismo antropológico y resuenan algunos de los autores que más alientan estas páginas, desde Wittgenstein a Weber, de Kant a Isaiah Berlin y Benjamin. Y entonces se entiende que el liberalismo no es una bandera para agitar con alegría, sino una salida para llevar sin apasionamiento. 
Son especialmente densos los apartados dedicados al sentido de la política, a la relación con la justicia o con la historia. Y con su densidad filosófica llega su belleza compositiva de forma y contenido: "como los hombres se mueren y no han sido capaces de conquistar una mediación con los dioses (...) parece evidente que solo se tienen a sí mismos en orden a adaptarse a este mundo hostil y perpetuarse. Es justamente tal hecho que exige postular la existencia de una relación entre el derecho finito y el ansia infinita de justicia (...) En dicha relación se concreta la actitud genuinamente liberal que venimos reclamando en este ensayo" (p. 204). La asunción del pluralismo de Berlin, en tanto afecta a valores y bienes, es el fundamento del individualismo. El ideal de igualdad liberal es que "todo ser humano tiene el mismo derecho a usar los recursos materiales de los que disponga para alcanzar los fines que les parecen mejores".

Por ello no es osado comenzar la lectura de este libro por el final, porque lo más importante del liberalismo es el ser humano, en la teoría y en la práctica, sin el cual no hay comunidad, no hay felicidad ni de uno ni de muchos. Es coherente que el capítulo quinto y final se dedique a intentar trazar un "retrato-robot" del llamado "individuo liberal", porque "el tercer liberalismo" que Galindo y Ujaldón han desbrozado en las páginas anteriores necesita una cierta actitud englobada en un término, ironía, que los autores toman directamente de Richard Rorty pero que se remonta a Sócrates y pasa por pensadores tan dispares como Montaigne o Nietzsche. El término tiene sus riesgos semánticos y por ello se esfuerzan en demarcarlo del "cínico". El liberal ironista es casi un héroe que soporta intelectualmente las aporías y tensiones infinitas de este "tercer liberalismo", se sabe conocedor de su fragilidad intelectual y no por ello se refugia en el calor de su hogar dando la espalda a la comunidad. El individuo ironista, el liberal de este libro, como Galindo y Ujaldón, participa en su comunidad mediante el diálogo consciente de su "insociable sociabilidad" y de la "frialdad" de la recompensa de su empeño colectivo. Pero no hay otra salida, ni para él ni para los suyos. "Solo un individuo irónico es capaz de asumir esa moderación de las expectativas que promueve el tercer liberalismo. Solo alguien irónico, esto es, que se haya desprendido de todo sentido absoluto y de promesas de felicidad completa, puede con-formarse con la palabra compartida como única fuente de sentido. Solo alguien así, justamente por no esperar ninguna redención trascendente ni revelación de verdad alguna, puede experimentar el justo valor de la solidaridad y hacer suyos los sufrimientos de los demás" (p.290).

Como James Stewart en "El hombre que mató a Liberty Valance", el ironista liberal no deja de creer en el valor de sus creencias aunque las sepa finitas en su eficacia; cree en la razón, la palabra y la ley para que la comunidad sobreviva, pero sabe también que hay dificultades en la realidad que parecen insalvables hasta que llega Tom Doniphon. Porque sabe y cuenta la dura verdad, el abogado Ransom Stodard no es un cínico: es un héroe, un tipo de heroísmo ciudadano, cotidiano y tranquilo, que demanda hoy una cultura política liberal en nuestra sociedad, tal y como nos la expone reconstruida y actualizada este ensayo imprescindible. 